Supporting Information for

\title{
Quantifying overlapping and differing information of global precipitation for GCM forecasts and EI Niño-Southern Oscillation
}

Tongtiegang Zhao ${ }^{1}$, Haoling Chen ${ }^{1}$, Yu Tian ${ }^{2}$ and Xiaohong Chen ${ }^{1}$

${ }^{1}$ Center of Water Resources and Environment, Southern Marine Science and Engineering Guangdong Laboratory (Zhuhai), School of Civil Engineering, Sun Yat-Sen University, Guangzhou, China

${ }^{2}$ Department of Water Resources, China Institute of Water Resources and Hydropower Research, Beijing, China

Correspondence to: Tongtiegang Zhao (zhaottg@ mail.sysu.edu.cn)

\section{Contents of this file}

Figures S1 to S8 illustrating the eight patterns of overlapping and differing information by season

Figures S9 to S12 illustrating the eight patterns at the lead times of 1 month and 2 months

Figures S13 to S16 illustrating the eight patterns under the significance levels of 0.05 and 0.01

Figures S17 to S18 illustrating the eight patterns for the Indian Ocean Dipole (IOD) in December-January-February 

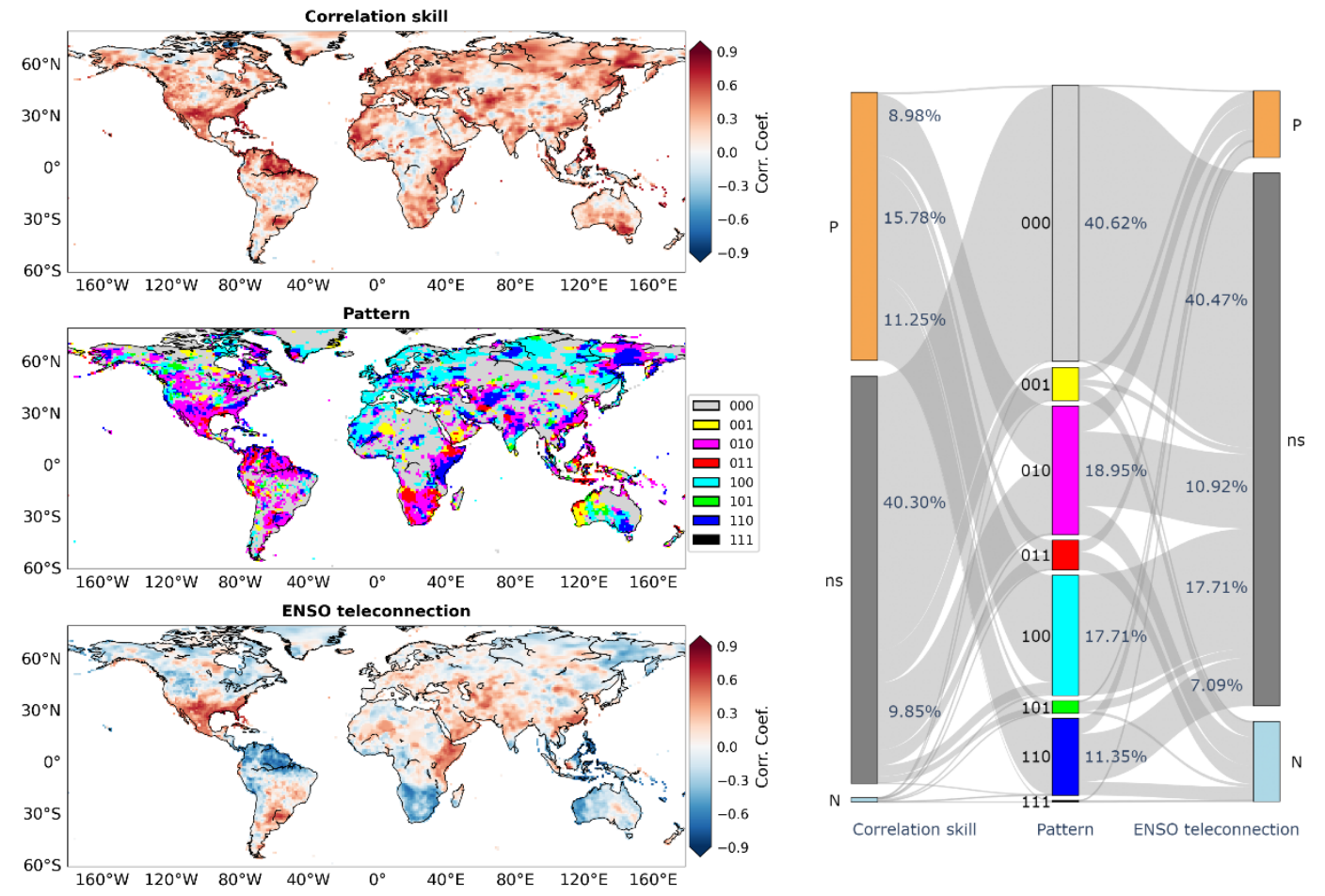

Figure S1. Spatial distribution of the eight patterns of overlapping and differing information in December-January-February (DJF). The significance level is set as 0.10 and the correlation skill is for the CFSv2 forecasts at the lead time of $\mathbf{0}$ month 

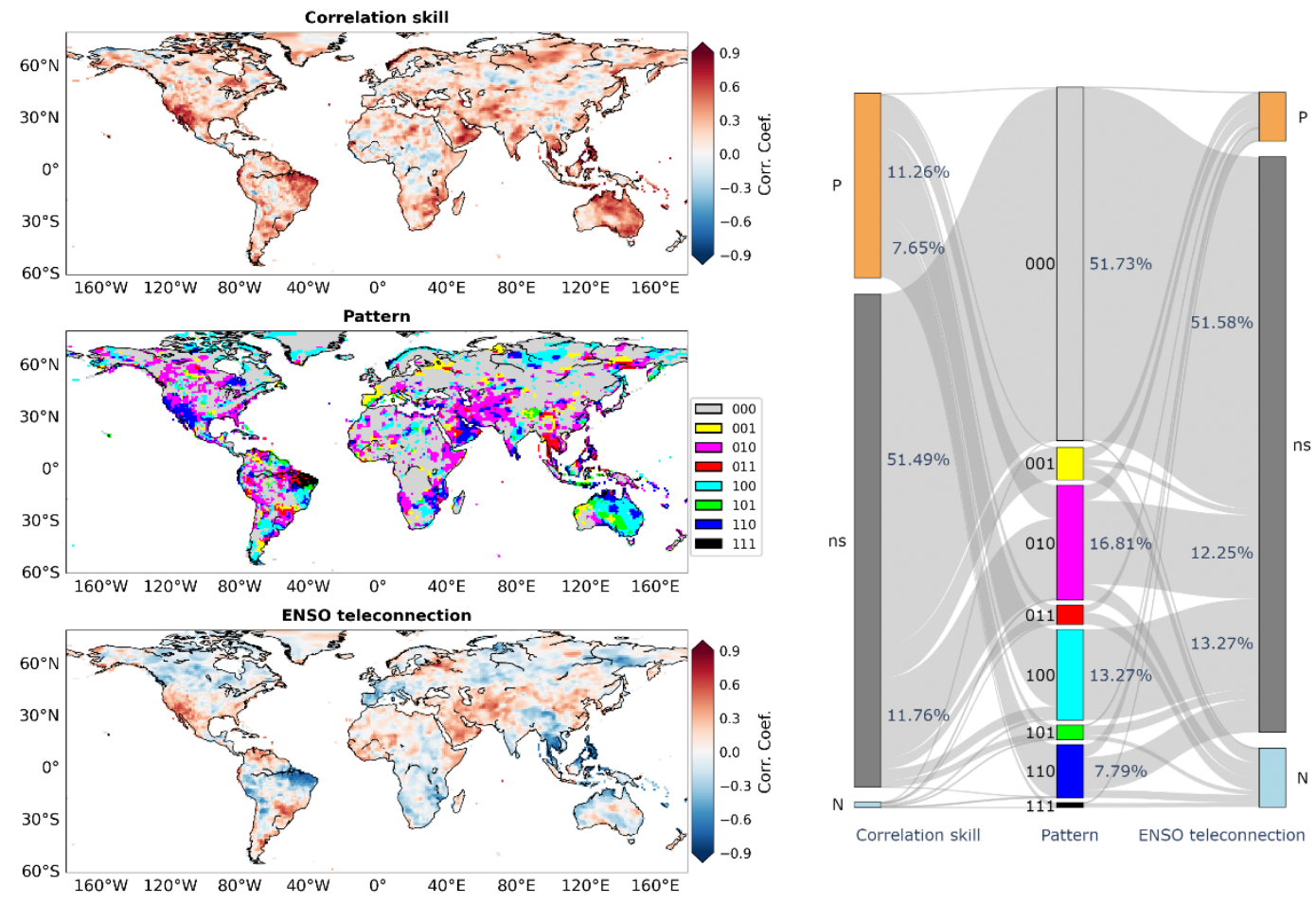

Figure S2. As for Figure S1, but for March-April-May (MAM) 

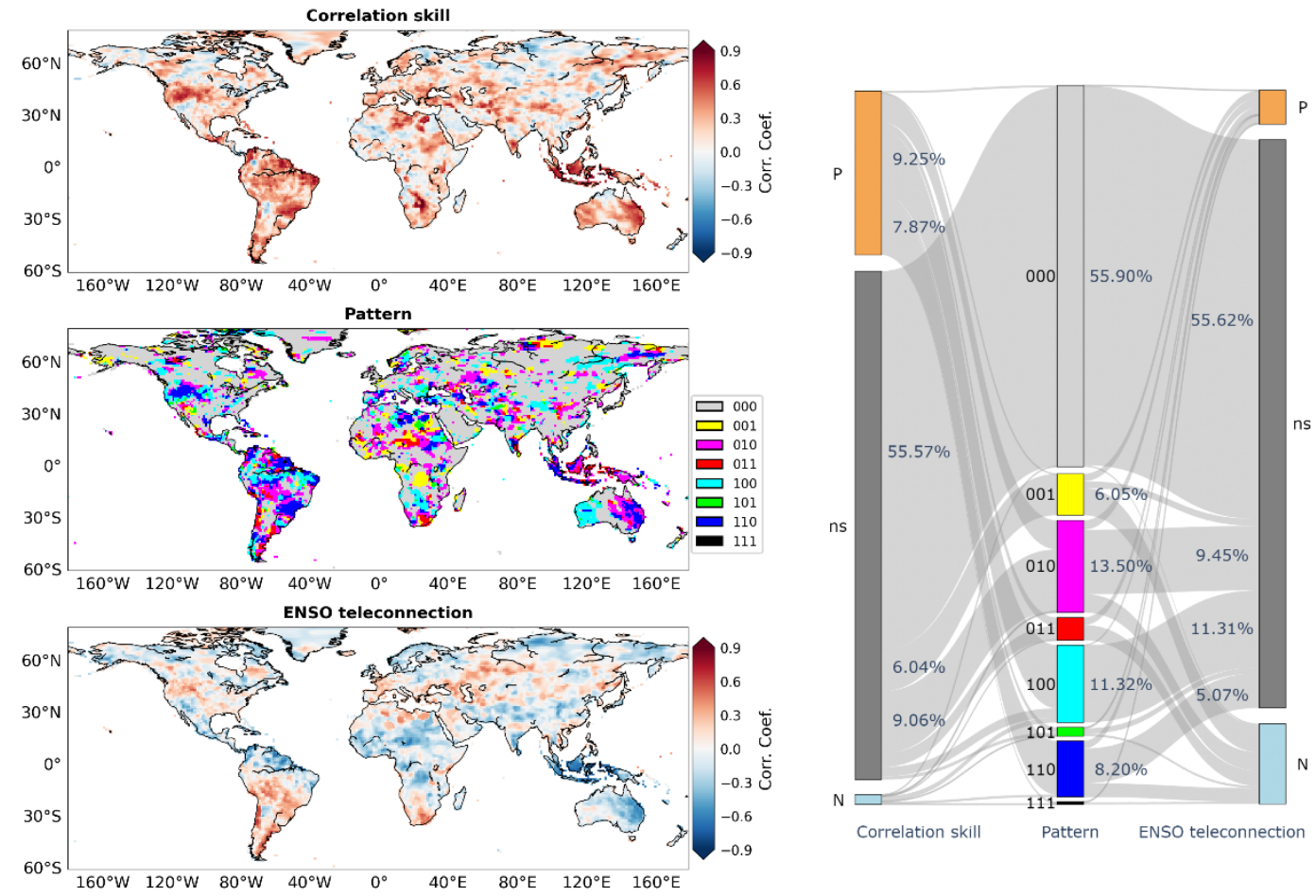

Figure S3. As for Figure S1, but for June-July-August (JJA) 

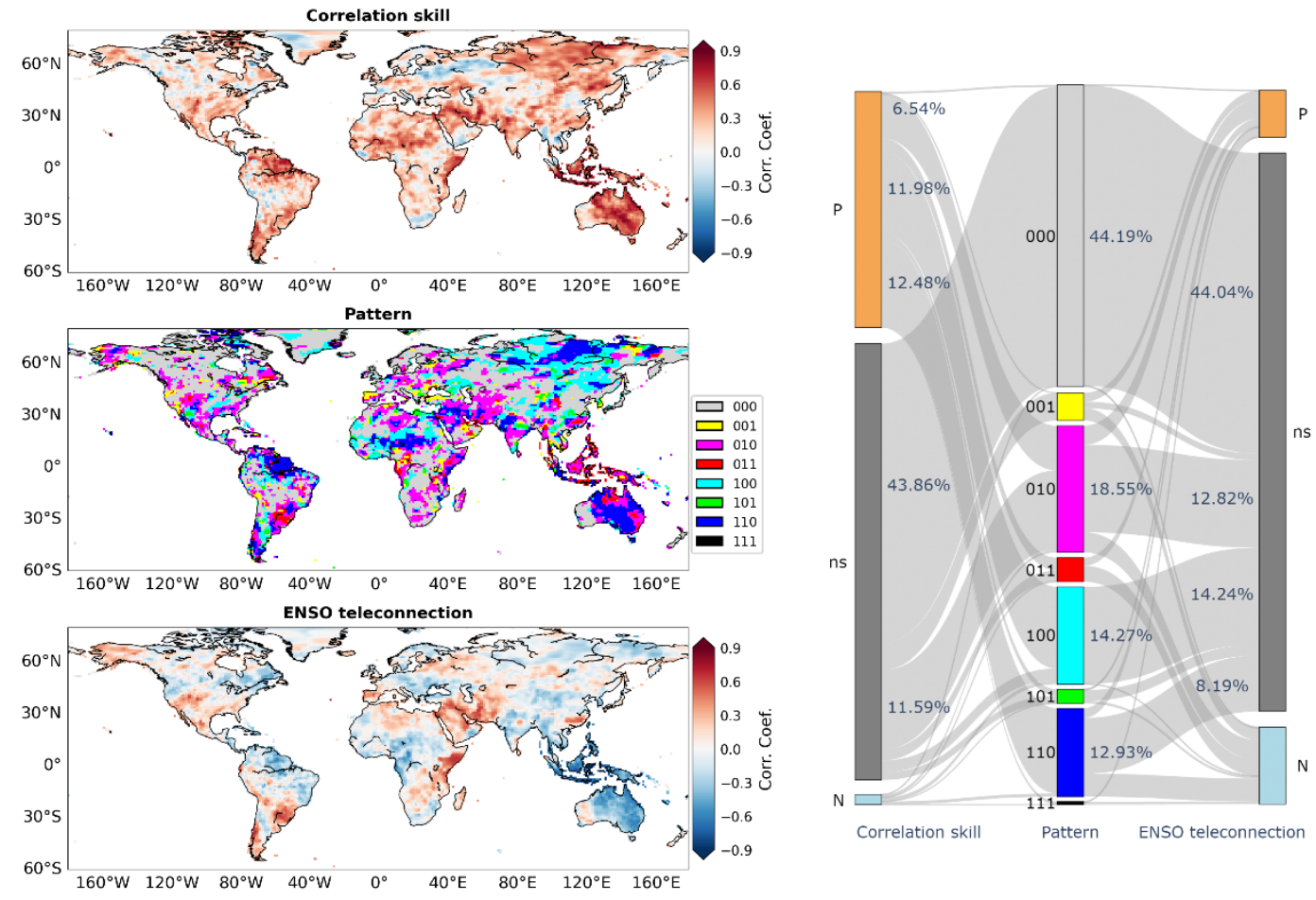

Figure S4. As for Figure S1, but for September-October-November (SON) 
(a) 000

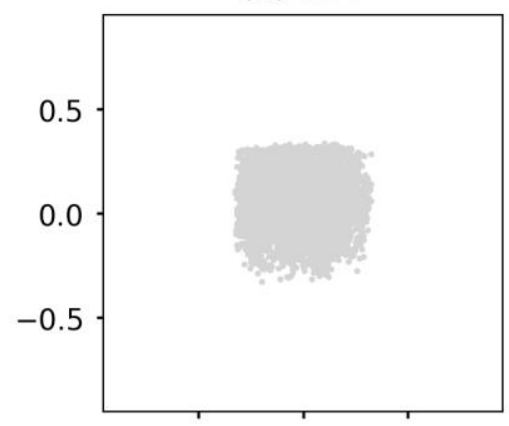

(d) 011

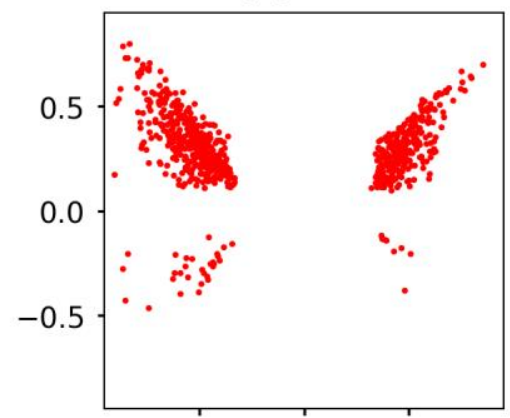

(g) 101

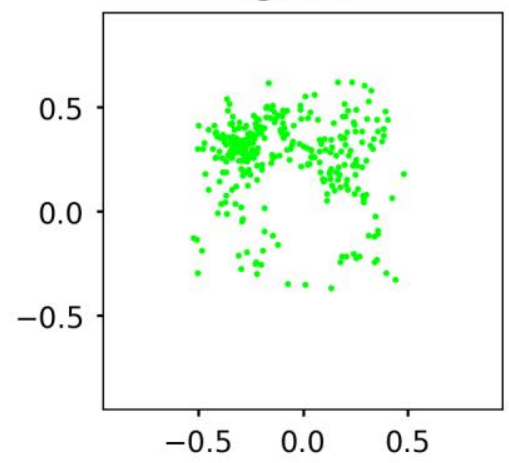

(b) 001

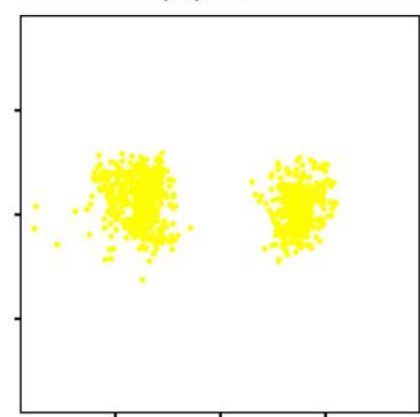

(e) all

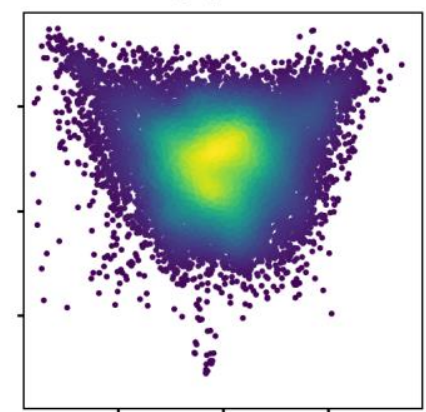

(h) 110

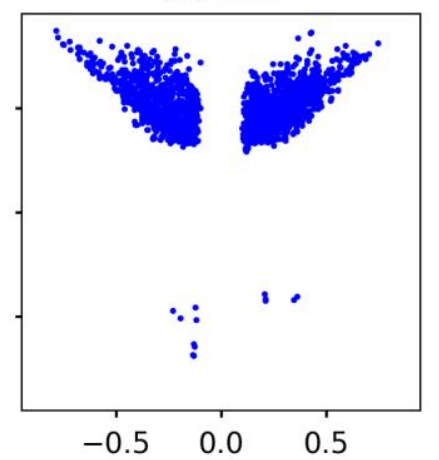

(c) 010

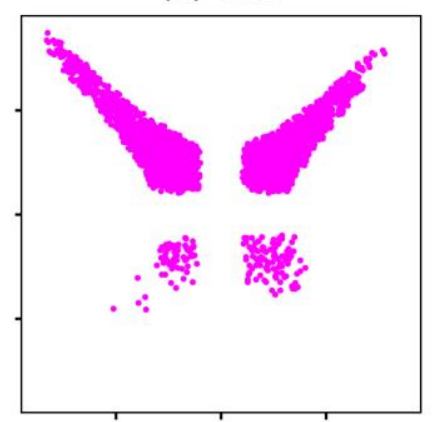

(f) 100

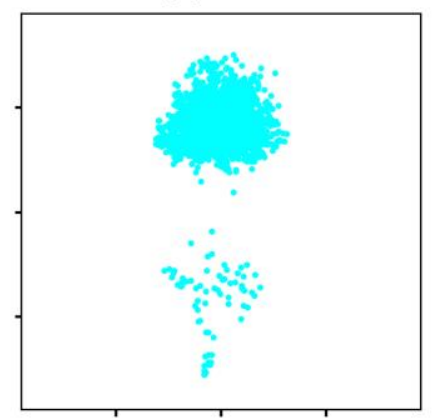

(i) 111

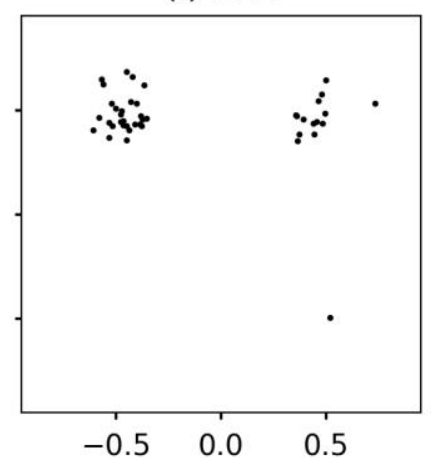

Figure S5. Scatter plots of correlation skill against ENSO teleconnection under the eight patterns in December-January-February (DJF). The significance level is set as 0.10 and the correlation skill is for the CFSv2 forecasts at the lead time of 0 month 
(a) 000

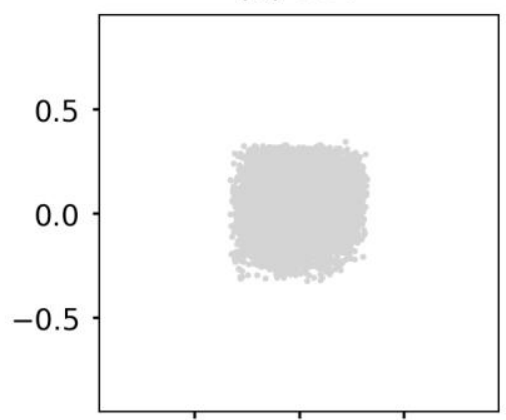

(d) 011

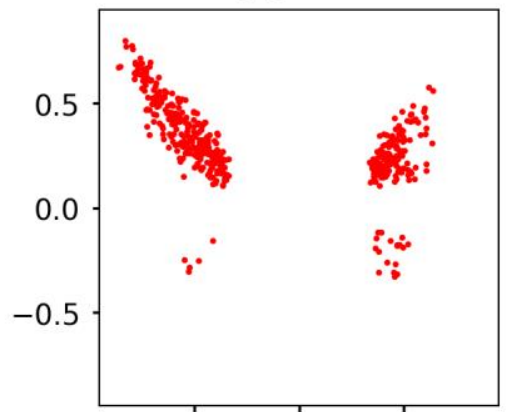

(g) 101

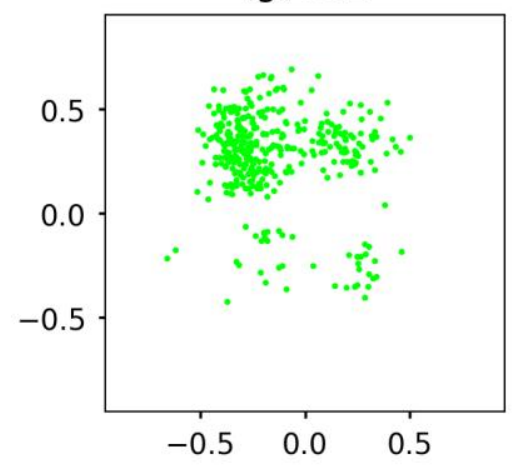

(b) 001

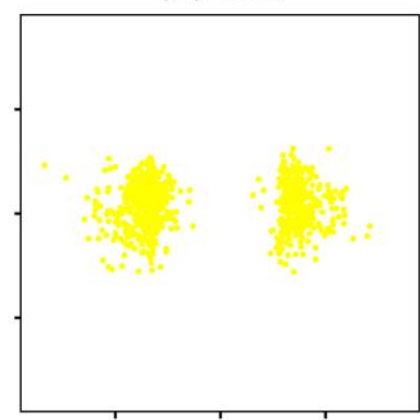

(e) all

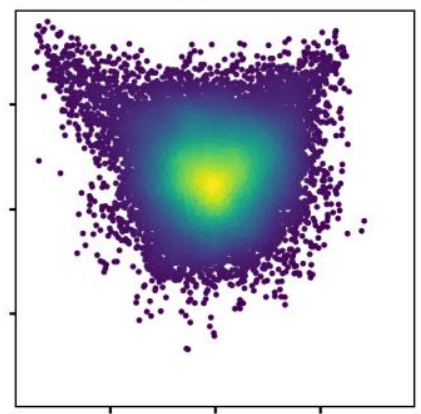

(h) 110

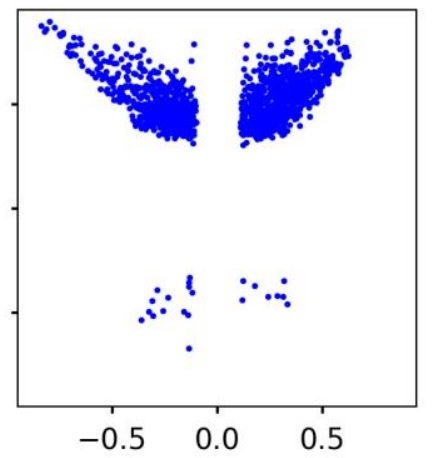

(c) 010

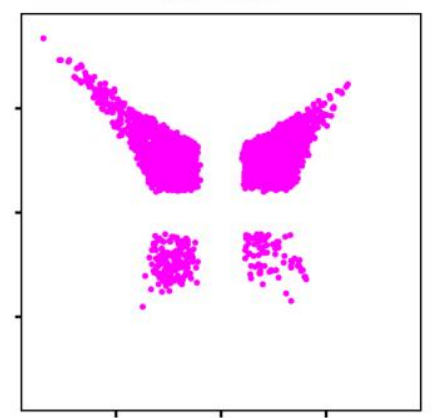

(f) 100

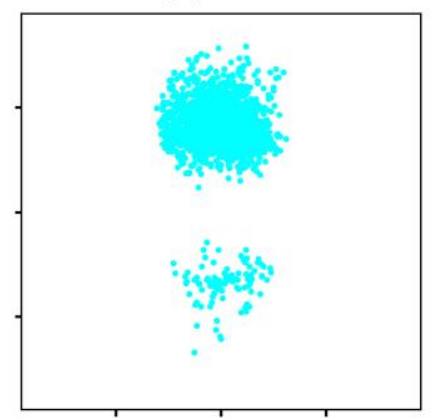

(i) 111

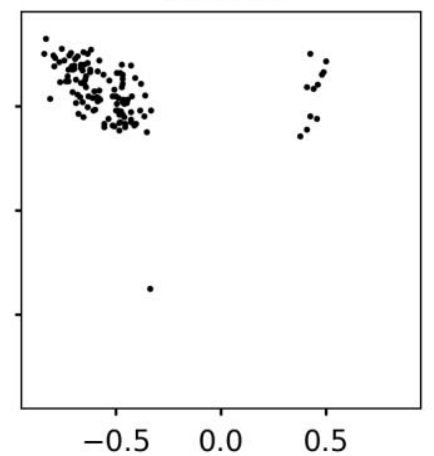

Figure S6. As for Figure S5, but for March-April-May (MAM) 
(a) 000

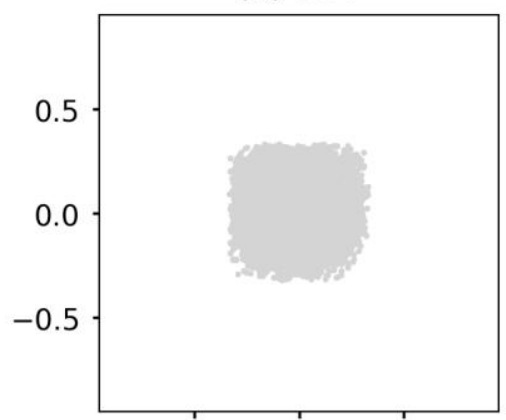

(d) 011

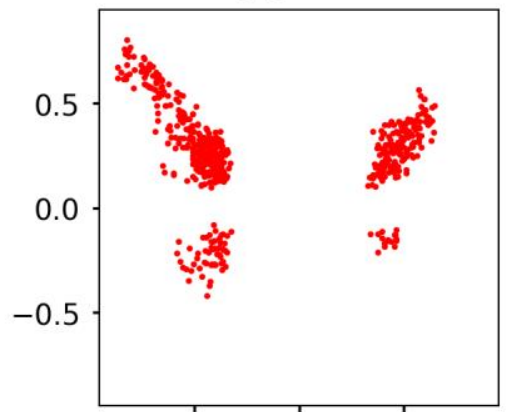

(g) 101

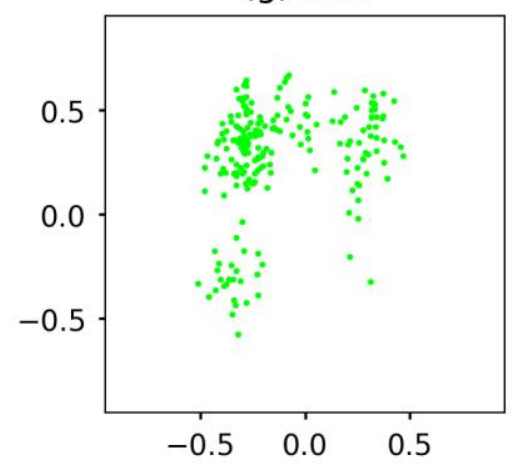

(b) 001

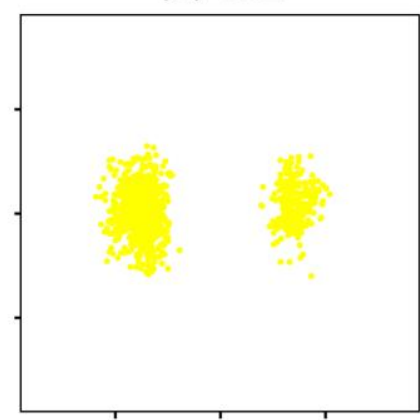

(e) all

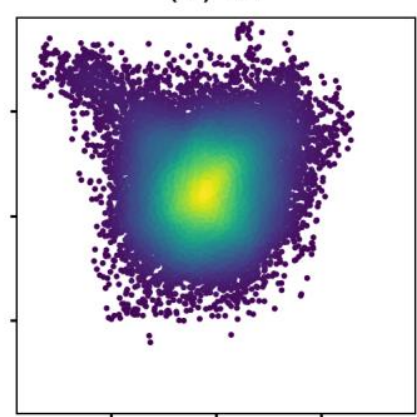

(h) 110

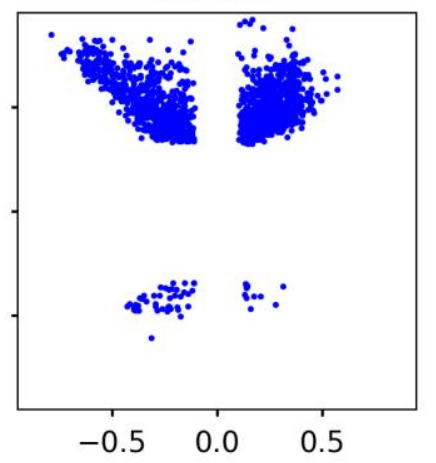

(c) 010

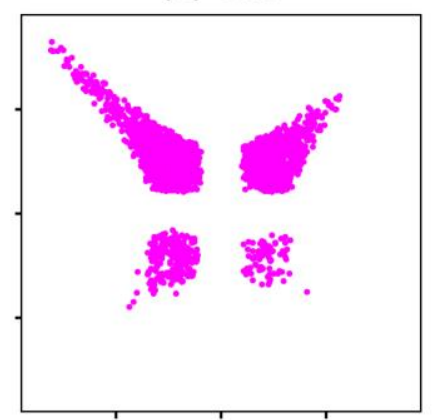

(f) 100

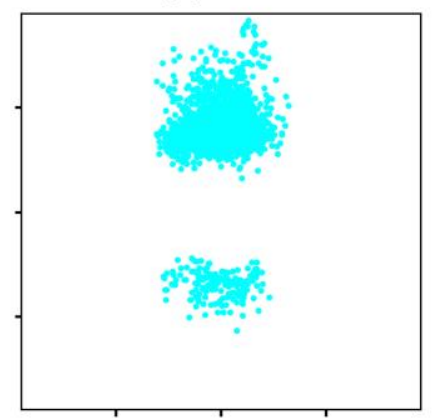

(i) 111

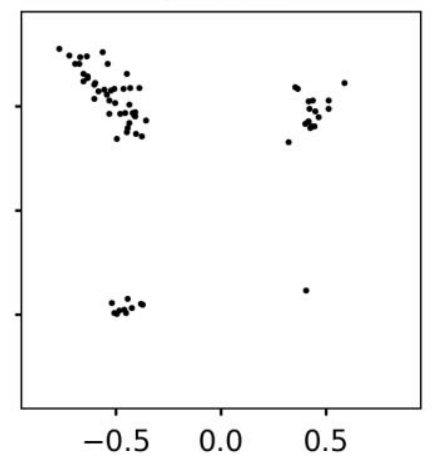

Figure S7. As for Figure S5, but for June-July-August (JJA) 
(a) 000

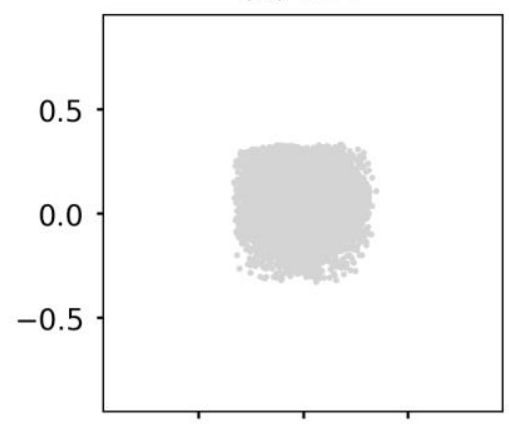

(d) 011

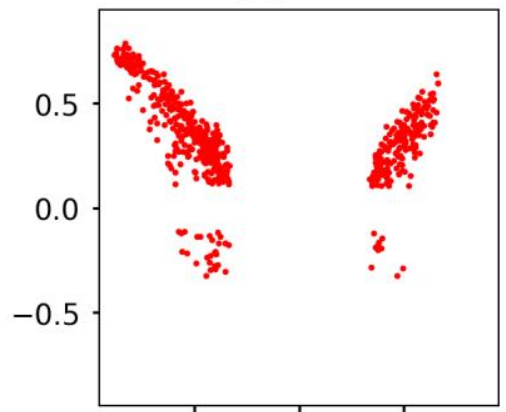

(g) 101

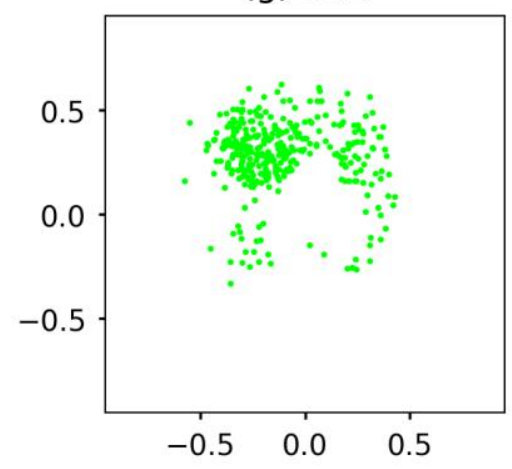

(b) 001

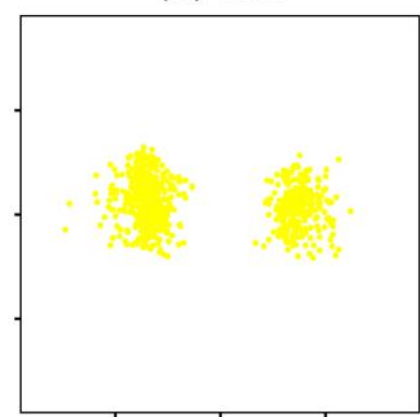

(e) all

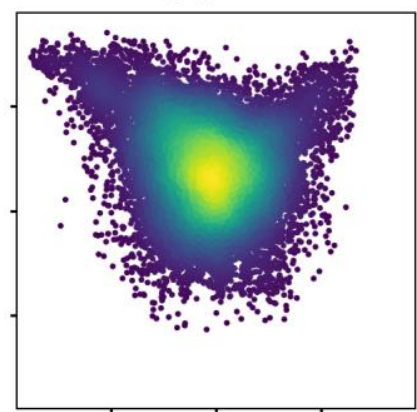

(h) 110

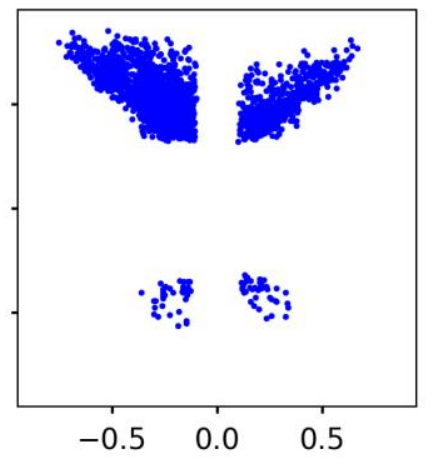

(c) 010

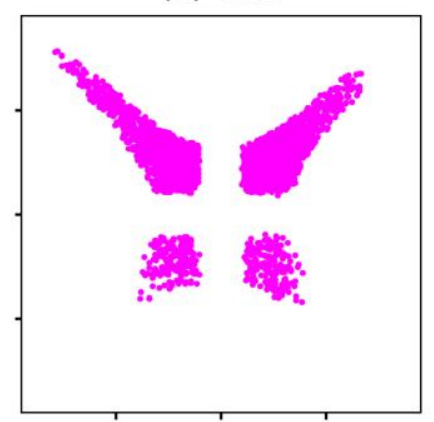

(f) 100

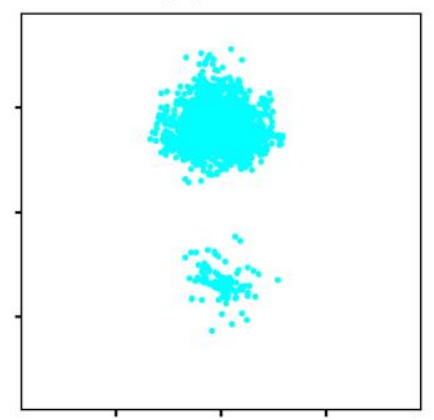

(i) 111

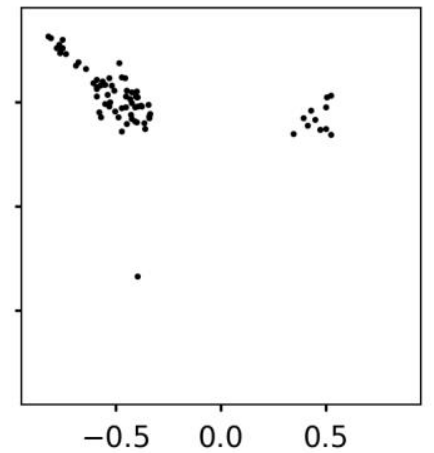

Figure S8. As for Figure S5, but for September-October-November (SON) 

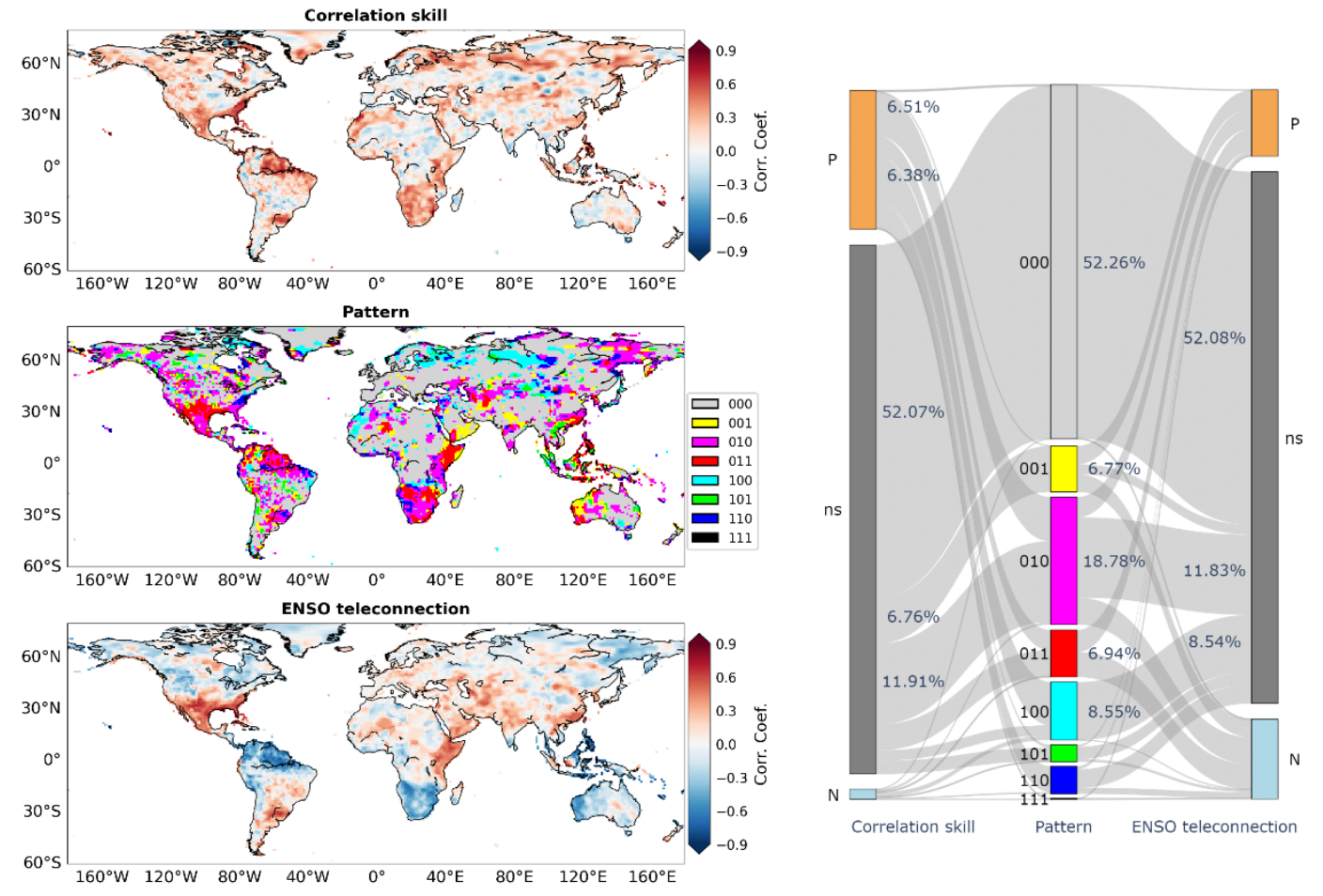

Figure S9. As for Figure S1, but for CFSv2 forecasts at the lead time of 1 month
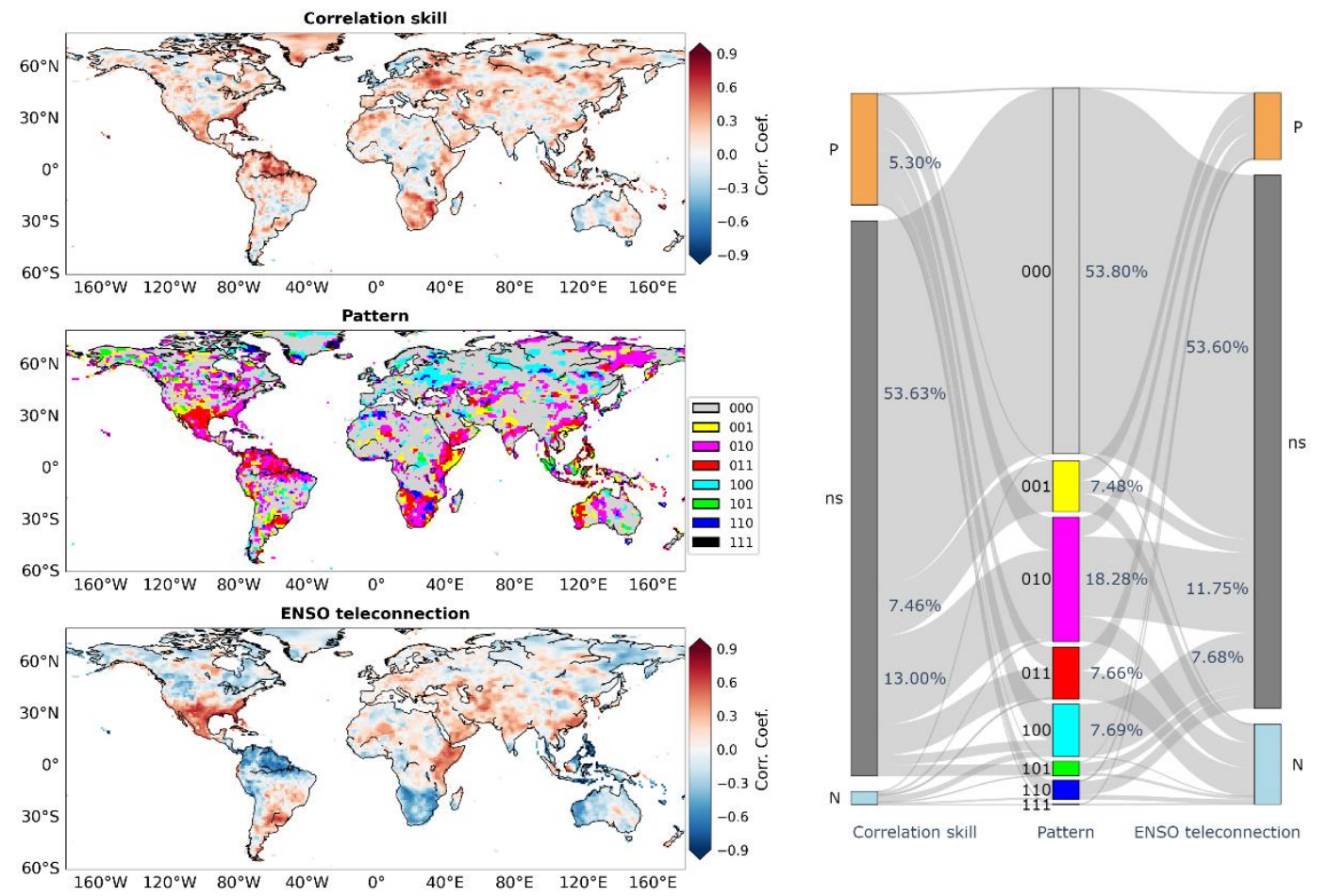

Figure S10. As for Figure S1, but for CFSv2 forecasts at the lead time of 2 months 
(a) 000

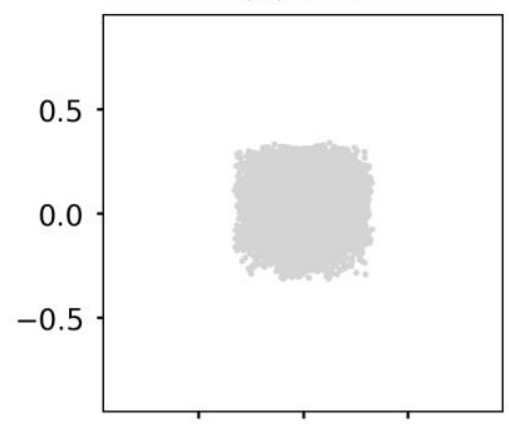

(d) 011

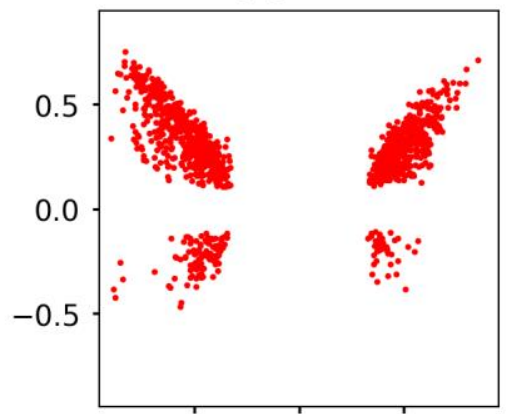

(g) 101

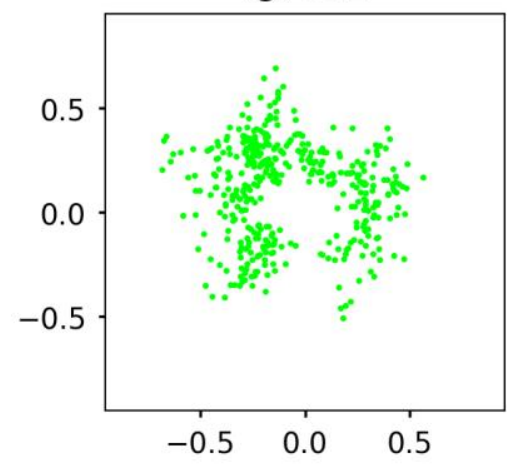

(b) 001

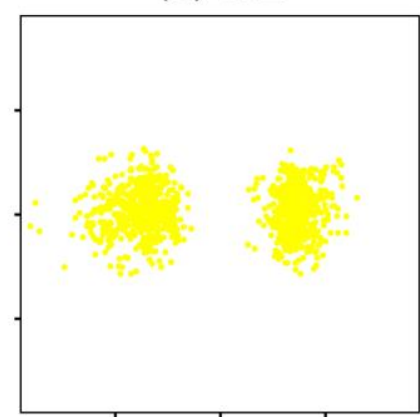

(e) all

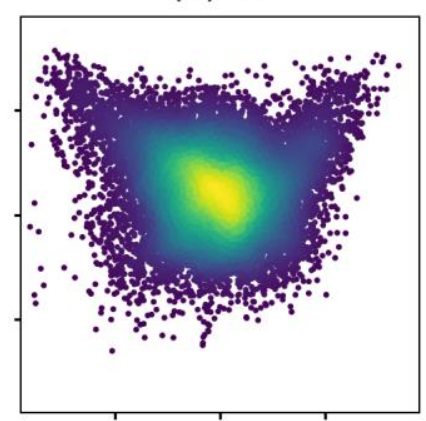

(h) 110

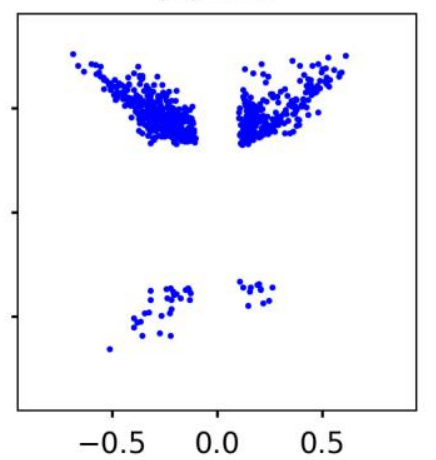

(c) 010

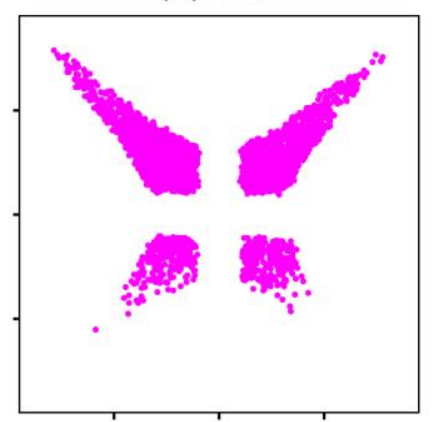

(f) 100

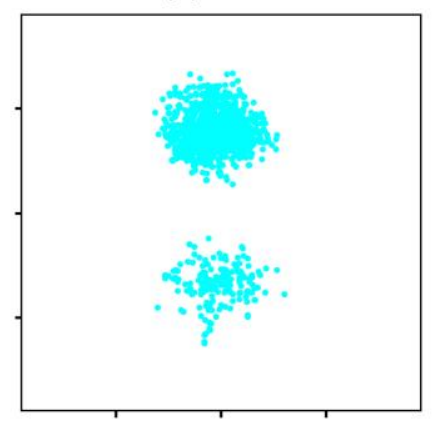

(i) 111

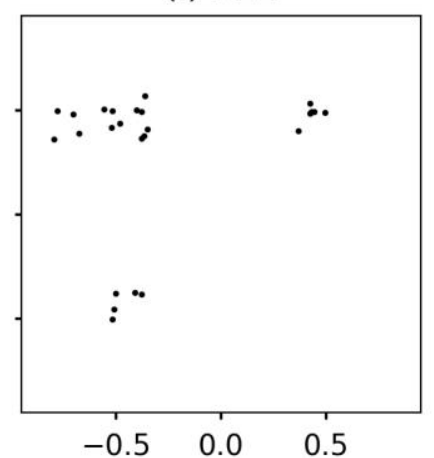

Figure S11. As for Figure S5, but for CFSv2 forecasts at the lead time of 1 month 
(a) 000

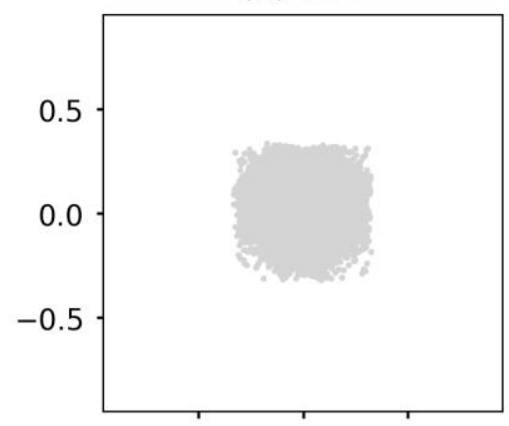

(d) 011

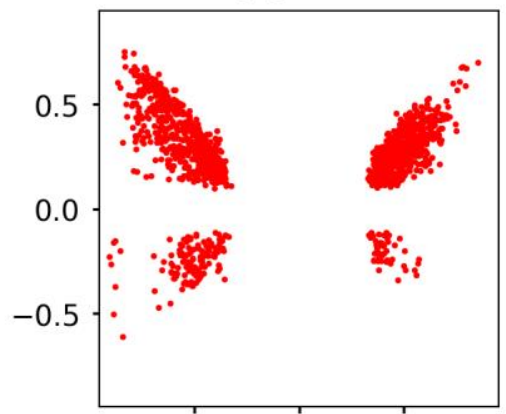

(g) 101

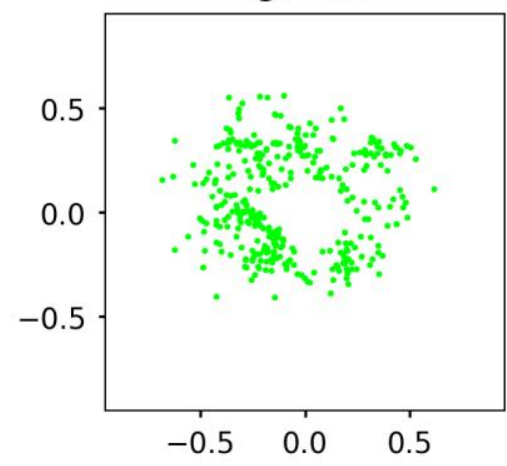

(b) 001

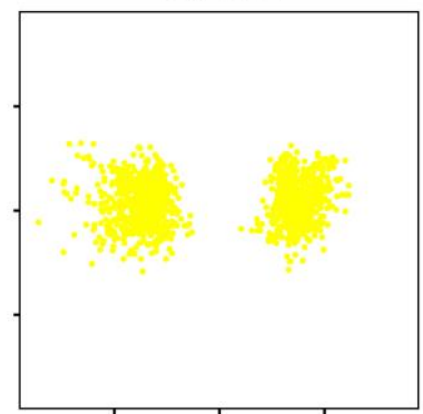

(e) all

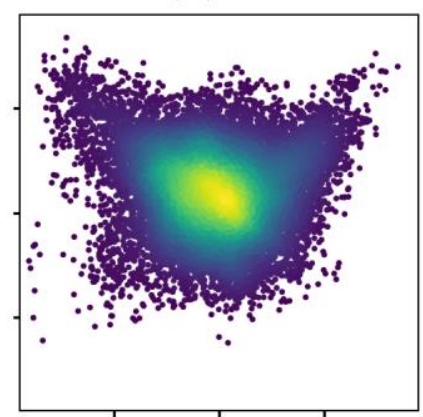

(h) 110

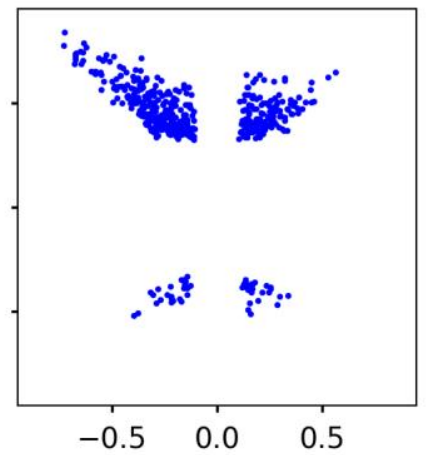

(c) 010

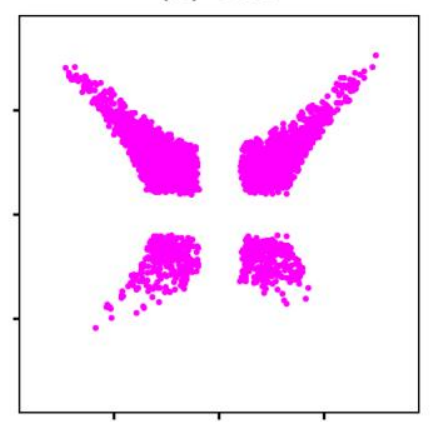

(f) 100

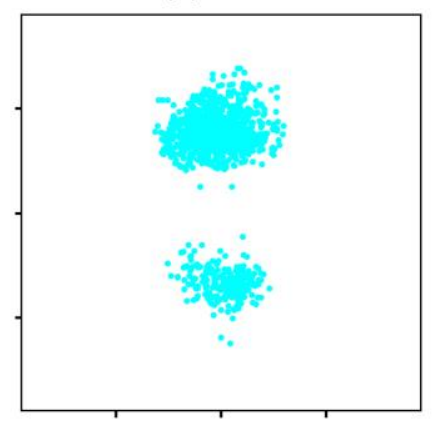

(i) 111

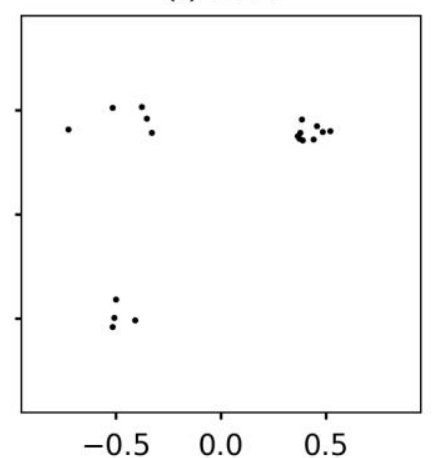

Figure S12. As for Figure S5, but for CFSv2 forecasts at the lead time of 2 months 


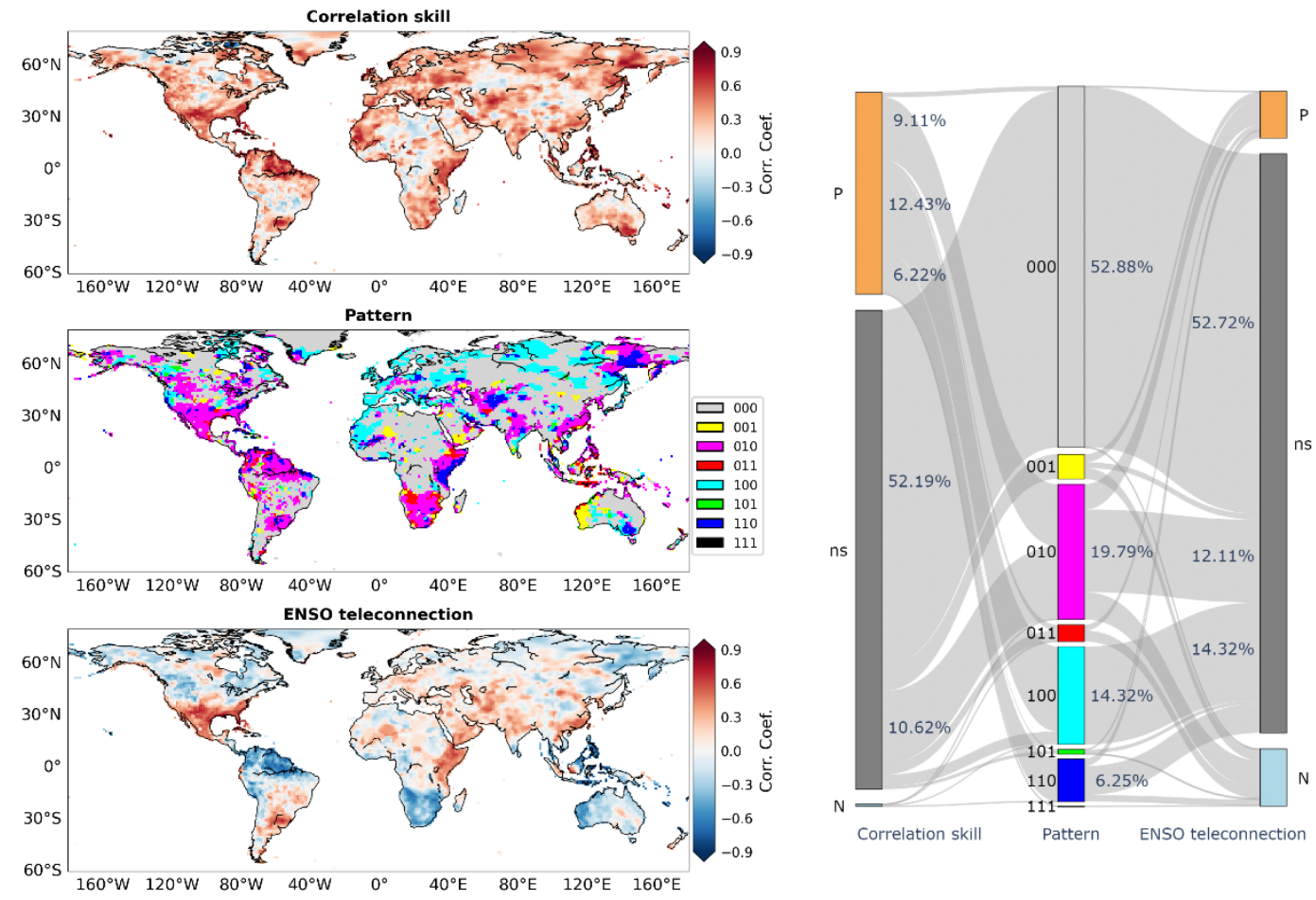

Figure S13. As for Figure S1, but for the significance level of 0.05

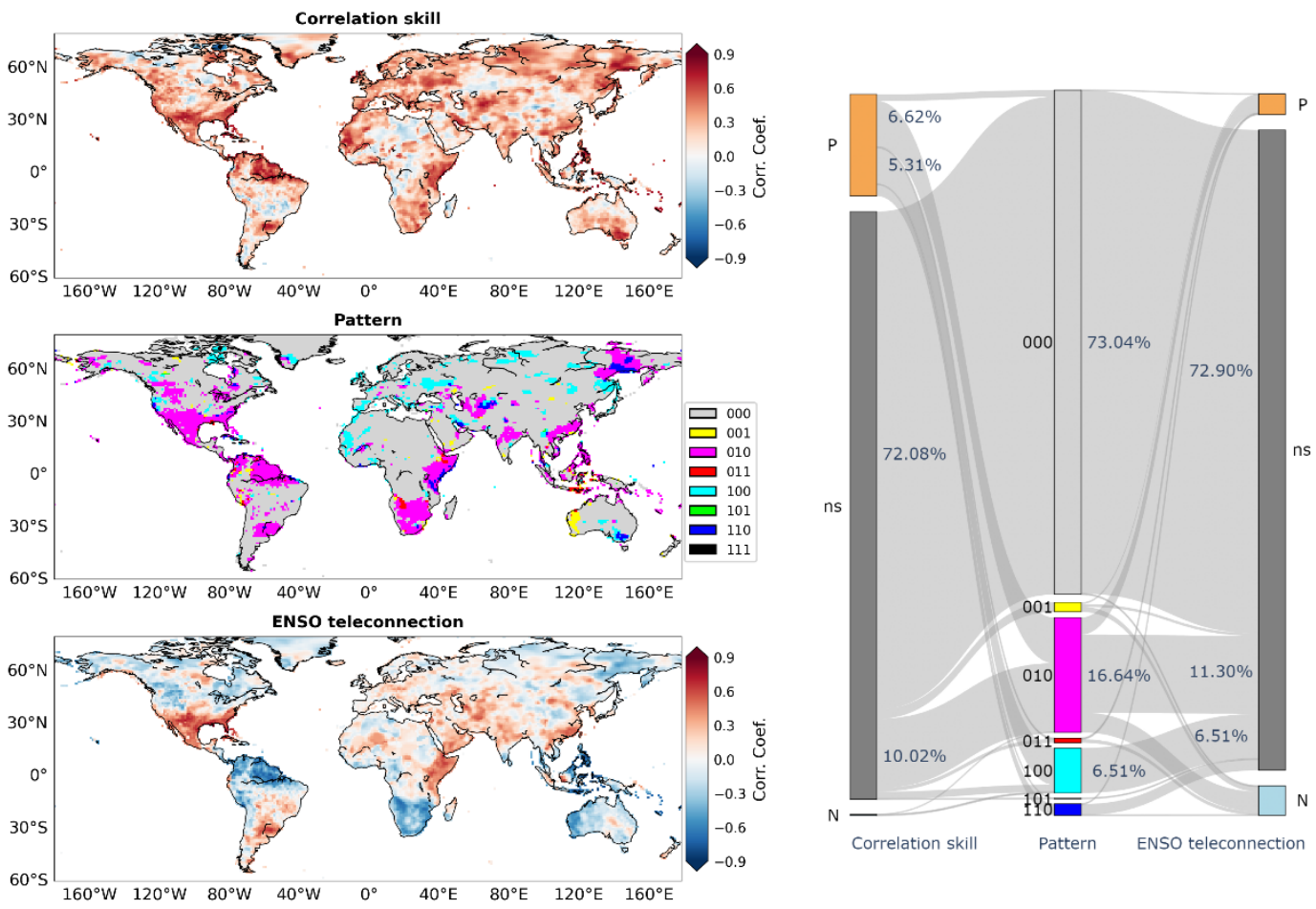

Figure S14. As for Figure S1, but for the significance level of 0.01 
(a) 000

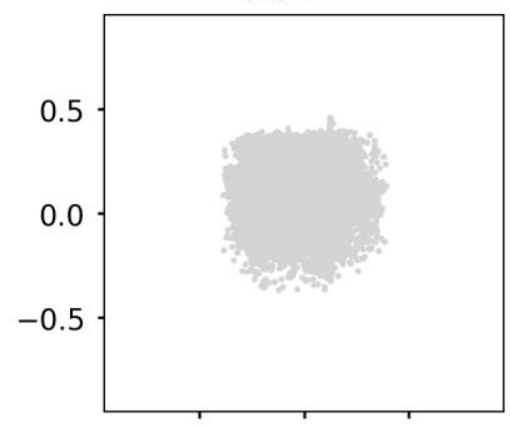

(d) 011

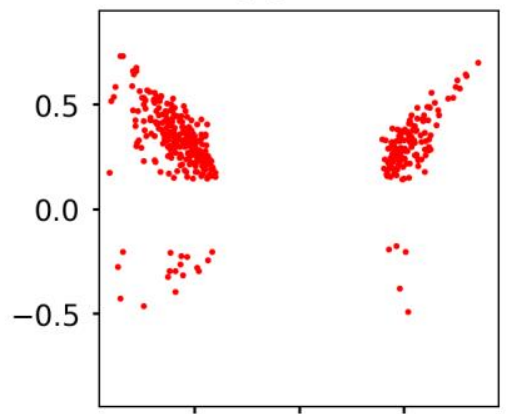

(g) 101

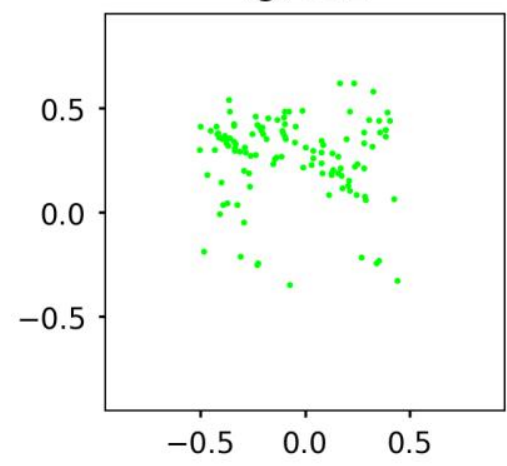

(b) 001

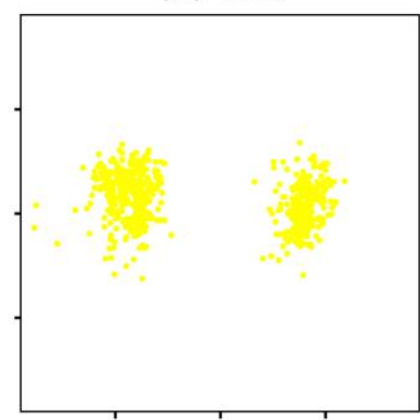

(e) all

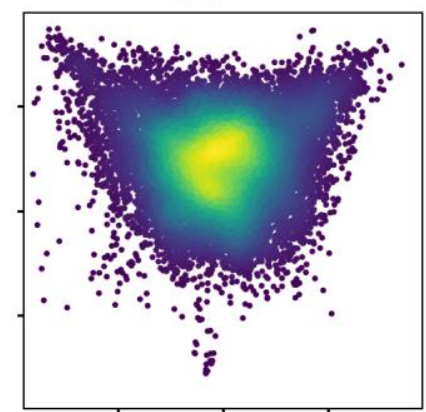

(h) 110

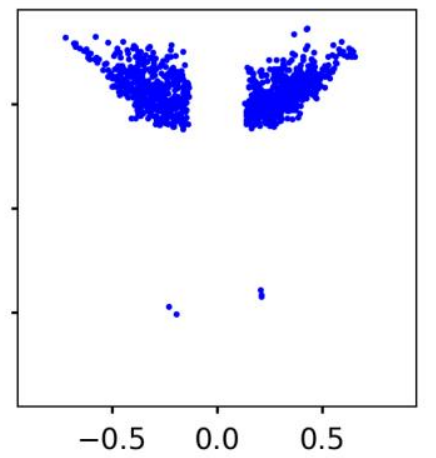

(c) 010

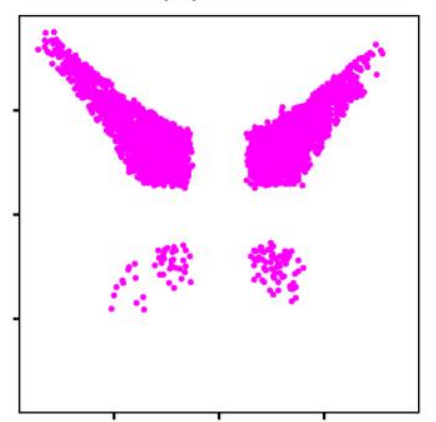

(f) 100

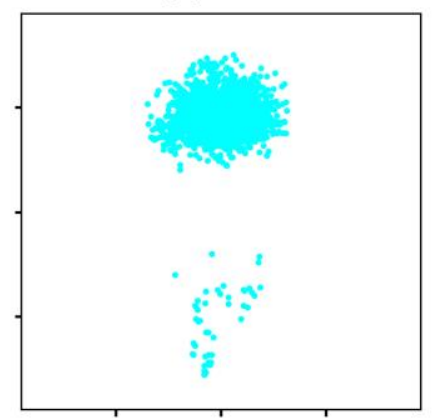

(i) 111

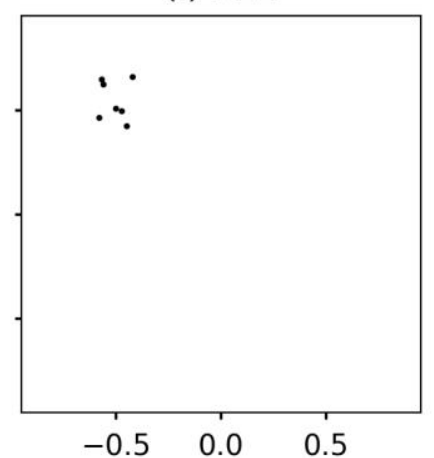

Figure S15. As for Figure S5, but for the significance level of 0.05 
(a) 000

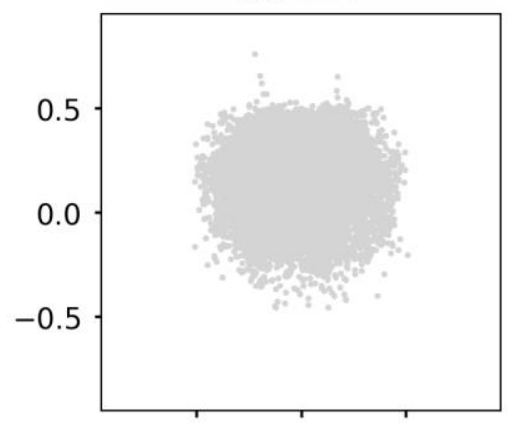

(d) 011

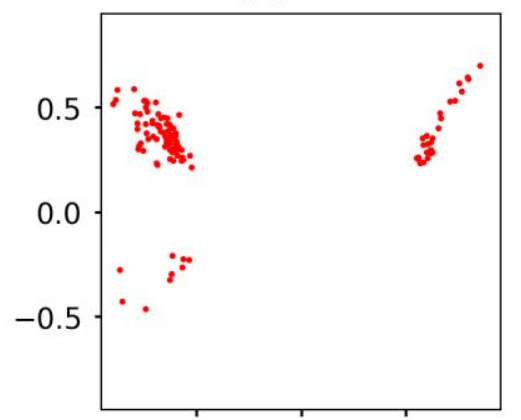

(g) 101

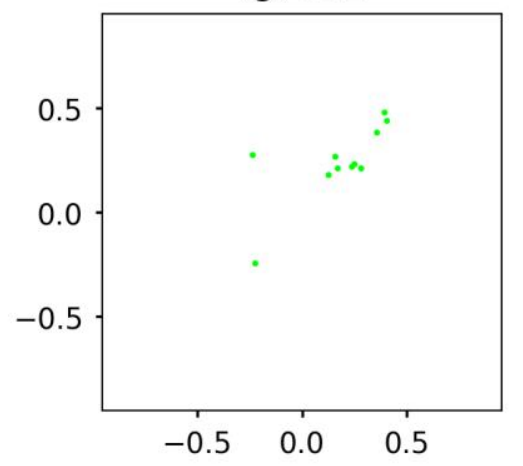

(b) 001

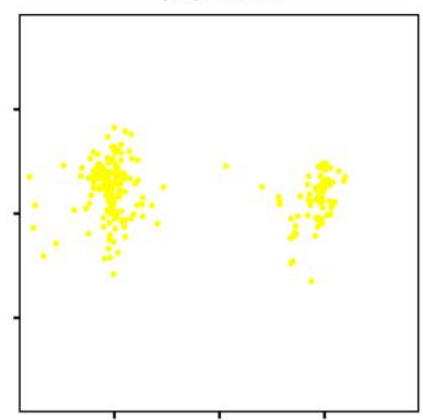

(e) all

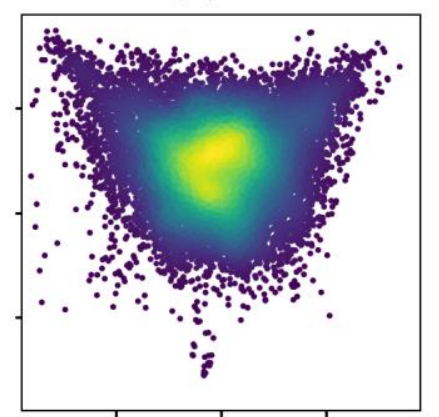

(h) 110

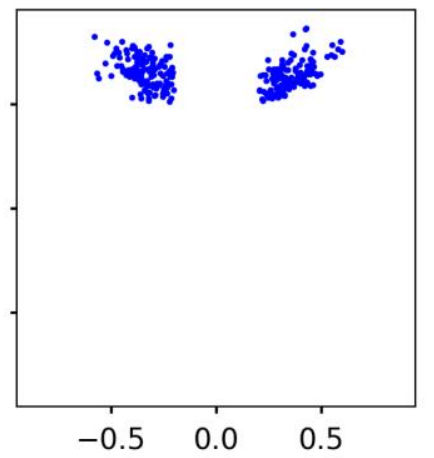

(c) 010

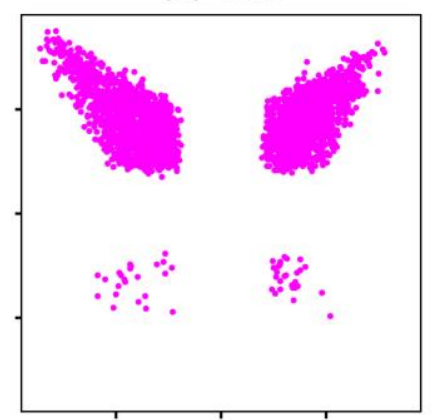

(f) 100
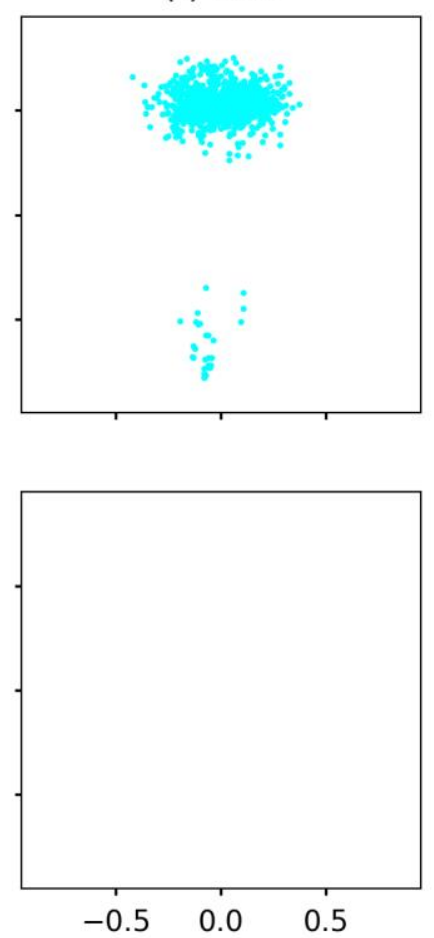

Figure S16. As for Figure S5, but for the significance level of 0.01 

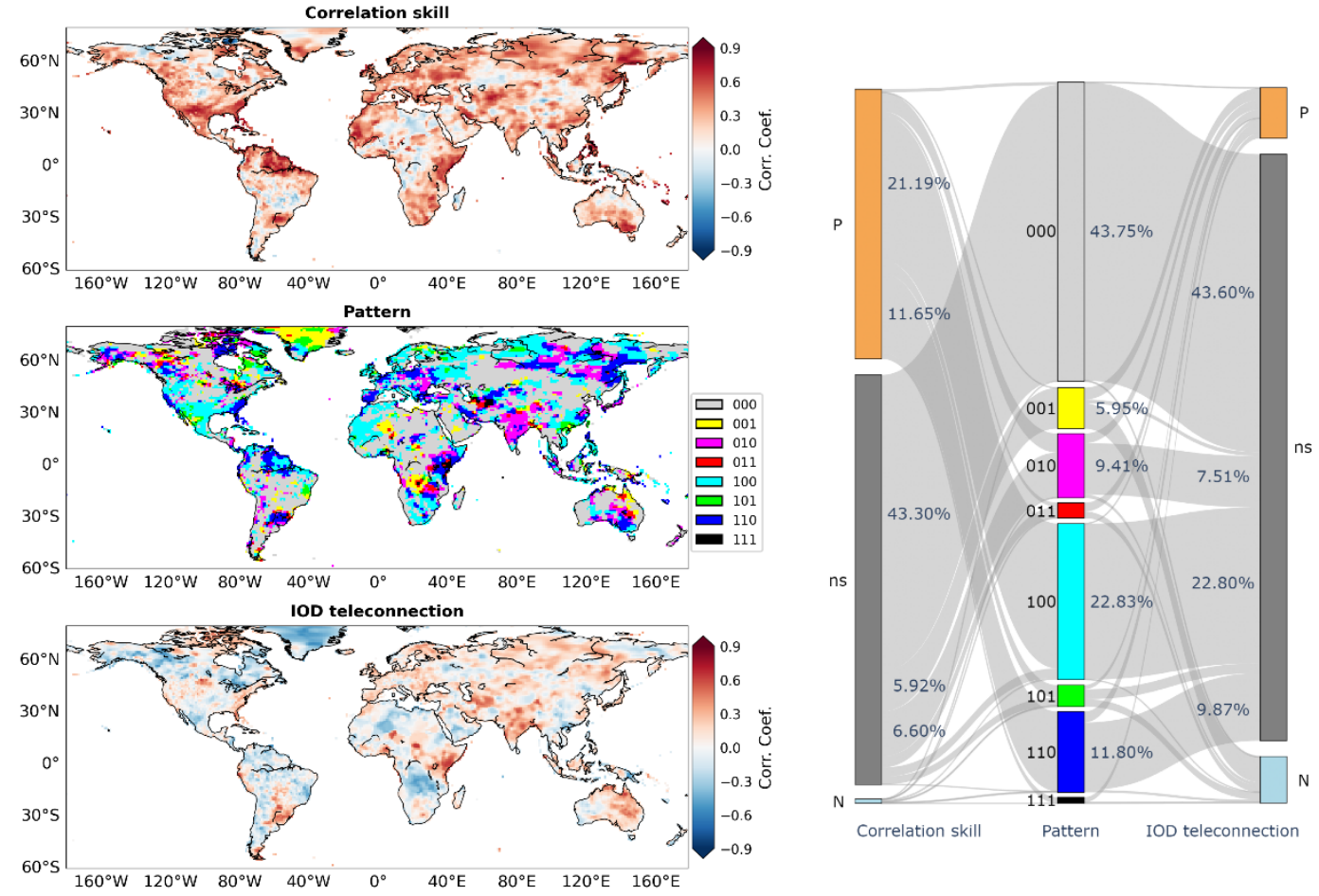

Figure S17. As for Figure S1, but for IOD in DJF 
(a) 000

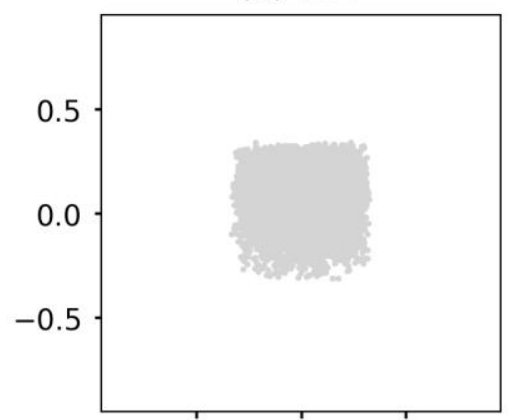

(d) 011

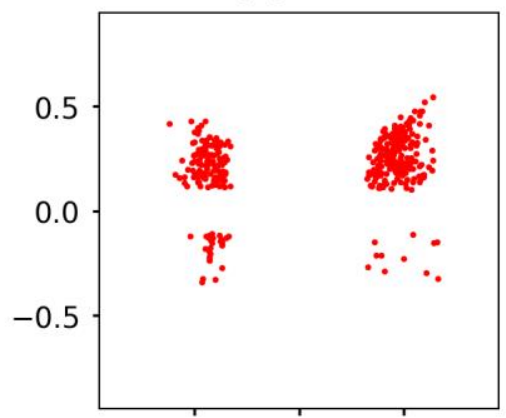

(g) 101

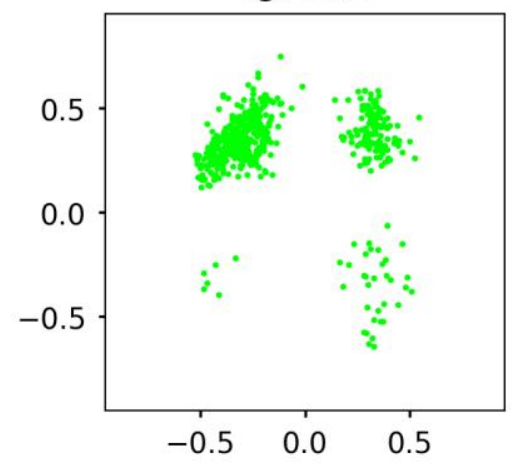

(b) 001

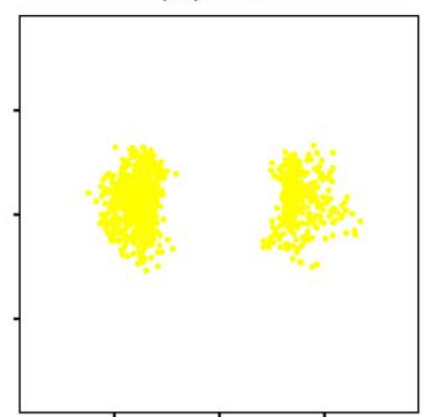

(e) all

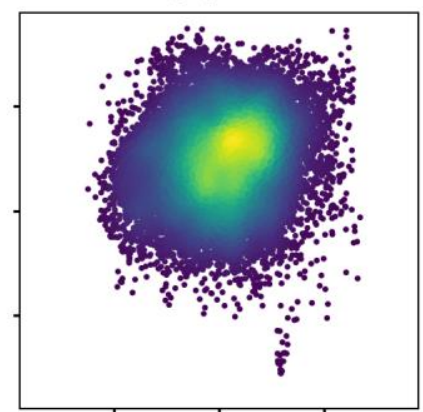

(h) 110

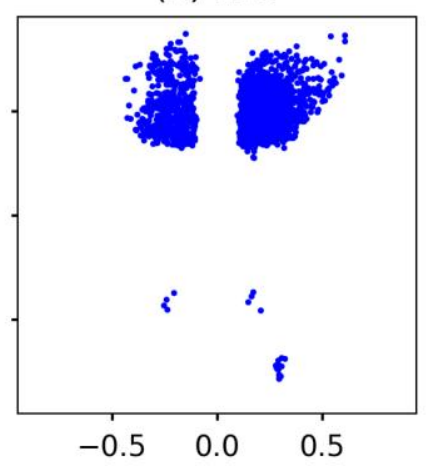

(c) 010

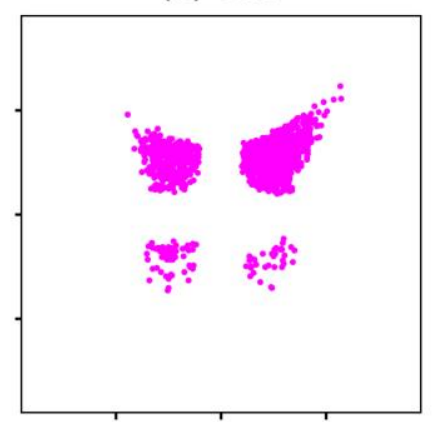

(f) 100

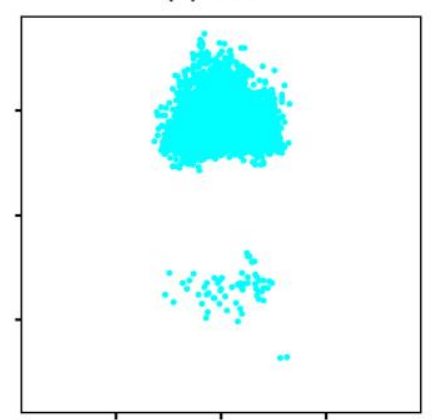

(i) 111

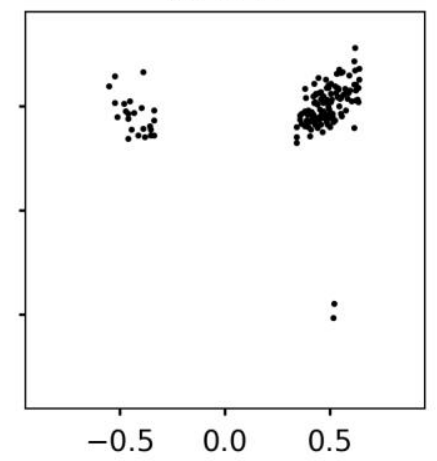

Figure S18. As for Figure S5, but for IOD in DJF 